\title{
Pediatric intracranial gunshot wounds: the Memphis experience
}

\author{
Michael DeCuypere, MD, PhD, ${ }^{1}$ Michael S. Muhlbauer, MD, ${ }^{1-3}$ Frederick A. Boop, MD, ${ }^{1-3}$ and \\ Paul Klimo Jr., MD, MPH ${ }^{1-3}$
}

1Department of Neurosurgery, University of Tennessee Health Science Center; ${ }^{2}$ Semmes-Murphey Neurologic and Spine Institute; and 'Le Bonheur Neuroscience Institute, Le Bonheur Children's Hospital, Memphis, Tennessee

\begin{abstract}
OBJECTIVE Penetrating brain injury in civilians is much less common than blunt brain injury but is more severe overall. Gunshot wounds (GSWs) cause high morbidity and mortality related to penetrating brain injury; however, there are few reports on the management and outcome of intracranial GSWs in children. The goals of this study were to identify clinical and radiological factors predictive for death in children and to externally validate a recently proposed pediatric prognostic scale.
\end{abstract}

METHODS The authors conducted a retrospective review of penetrating, isolated GSWs sustained in children whose ages ranged from birth to 18 years and who were treated at 2 major metropolitan Level 1 trauma centers from 1996 through 2013. Several standard clinical, laboratory, and radiological factors were analyzed for their ability to predict death in these patients. The authors then applied the St. Louis Scale for Pediatric Gunshot Wounds to the Head, a scoring algorithm that was designed to provide rapid prognostic information for emergency management decisions. The scale's sensitivity, specificity, and positive and negative predictability were determined, with death as the primary outcome.

RESULTS Seventy-one children (57 male, 14 female) had a mean age of 14 years (range 19 months to 18 years). Overall mortality among these children was $47.9 \%$, with $81 \%$ of survivors attaining a favorable clinical outcome (Glasgow Outcome Scale score $\geq 4$ ). A number of predictors of mortality were identified (all $p<0.05$ ): 1) bilateral fixed pupils; 2) deep nuclear injury; 3) transventricular projectile trajectory; 4) bihemispheric injury; 5) injury to $\geq 3$ lobes; 6) systolic blood pressure < $100 \mathrm{~mm} \mathrm{Hg}$; 7) anemia (hematocrit < 30\%); 8) Glasgow Coma Scale score $\leq 5$; and 9) a blood base deficit $<-5 \mathrm{mEq} / \mathrm{L}$. Patient age, when converted to a categorical variable (0-9 or 10-18 years), was not predictive. Based on data from the 71 patients in this study, the positive predictive value of the St. Louis scale in predicting death (score $\geq 5$ ) was $78 \%$.

CONCLUSIONS This series of pediatric cranial GSWs underscores the importance of the initial clinical exam and CT studies along with adequate resuscitation to make the appropriate management decision(s). Based on our population, the St. Louis Scale seems to be more useful as a predictor of who will survive than who will succumb to their injury.

http://thejns.org/doi/abs/10.3171/2015.7.PEDS15285

KEY WORDS pediatric intracranial gunshot wound; survival; traumatic brain injury; pediatric management; trauma

$\mathrm{U}$ NFORTUNATELY, intracranial ballistic injuries due to firearms, most commonly inflicted by low-velocity handguns, are not uncommon events at many major US metropolitan Level 1 trauma centers. They often lead to severe neurological injury or death. Adult mortality rates from such injuries range between $50 \%$ and $90 \%$ in most series. ${ }^{1,6,9,10,12,13,15,20,27,31}$ Data from the Centers for Disease Control and Prevention (CDC) suggest that deaths due to intracranial gunshot wounds (GSWs) in the US may be rising. For instance, from 2004 to 2008 , the mortality rate from intracranial GSWs (all ages) was 6.10 deaths per 100,000 population (http://www.cdc.gov/injury/wisqars/ index.html). In the years 2004-2010, this rate rose to 6.34 deaths per 100,000 population. Unfortunately, the same trend was noted for pediatric patients (1.31 deaths per 100,000 population in 2004-2008 vs 1.42 deaths per 100,000 population in 2004-2010). In fact, firearm injury was the fifth leading violent cause of hospitalization for

ABBREVIATIONS GCS = Glasgow Coma Scale; GOS = Glasgow Outcome Scale; GSW = gunshot wound; ICP = intracranial pressure; INR = international normalized ratio; SBP = systolic blood pressure.

SUBMITTED May 8, 2015. ACCEPTED July 28, 2015.

INCLUDE WHEN CITING Published online January 5, 2016; DOI: 10.3171/2015.7.PEDS15285. 
US children in 2013 (http://www.cdc.gov/injury/wisqars/ index.html).

In the state of Tennessee, the annual death rate from intracranial GSWs (all ages) was 9.19 deaths per 100,000 population from 2004 to 2010 (http://www.cdc.gov/ injury/wisqars/index.html). The number of deaths over this time period was highest in Shelby County, where 561 people died from a GSW to the head. The annual death rate for intracranial GSWs in pediatric patients in the state of Tennessee was 1.60 deaths per 100,000 population, and again the rate was highest in Shelby County with 51 deaths over this 6-year period (http://www.cdc. gov/injury/wisqars/index.html).

Pediatric GSWs present a challenge to pediatric neurosurgeons owing to their relative rarity and the consequent paucity of literature. As suggested by some, caution should be exercised when making clinical corollaries from the literature on adults to the pediatric population..$^{2,711}$ As is the general rule for traumatic brain injury of any etiology, children typically have lower overall mortality and a greater propensity for neurological recovery than their adult counterparts, making it more difficult to prognosticate and administer appropriate intervention(s). 2,7,11,16,19,22,24

In 2012, Bandt et al. proposed the St. Louis Scale for Pediatric Gunshot Wounds to the Head. ${ }^{2}$ This tool, based on physical examination and imaging findings, is a scoring algorithm that rapidly provides prognostic information to clinicians for guidance in emergency management decisions. The purpose of the present study was 2-fold: 1) to review our pediatric GSW experience in an attempt to identify predictors of death, and 2) to externally validate the St. Louis scale.

\section{Methods}

\section{Study Questions}

We sought to answer 2 questions with our research: 1) What are the predictors of mortality in children who have sustained a cranial penetrating (that is, through the skull, dura mater, and brain) GSW? 2) Can the St. Louis scale accurately predict survival and death in our patient population?

\section{Patient Selection and Outcomes}

This retrospective study was approved by the University of Tennessee Health Science Center Institutional Review Board. All pediatric patients presenting with gunshot injuries to the head who received care in Memphis, Tennessee, at Le Bonheur Children's Hospital or the Elvis Presley Memorial Trauma Center between 1996 and 2013 were initially screened for study inclusion. Patients were eligible if they suffered a firearm-induced, penetrating, intradural traumatic brain injury and were 18 years old or younger. Patients with multiple traumas, including concomitant extracranial penetrating injuries, were not included. Glasgow Outcome Scale (GOS) score at the last available follow-up was the primary outcome, with particular attention paid to a GOS score of 1 , which is defined as death.

\section{Medical and Surgical Management}

For patients in whom an intracranial pressure (ICP) monitor (intraparenchymal sensor or external ventricular drain) had been placed, the goal ICP was less than $20 \mathrm{~cm}$ $\mathrm{H}_{2} \mathrm{O}$ or $\mathrm{mm} \mathrm{Hg}$, utilizing any number of standard ICPlowering interventions. Concurrently, we attempted to maintain the cerebral perfusion pressure above 40-60 $\mathrm{mm} \mathrm{Hg}$, depending on the age of the child, by using intravenous fluids and vasopressors. Barbiturate coma was induced only if all medical and surgical options had been exhausted.

When surgery was performed, we followed principles consistent with what was published in the American Association of Neurological Surgeons (AANS)/Congress of Neurological Surgeons (CNS) guidelines for the surgical management of penetrating brain injury. ${ }^{29}$ Surgery was undertaken in all adequately resuscitated patients who we believed could survive their injury. It is our general philosophy that if the neurological exam and imaging studies support meaningful survival or if there is a reasonable chance of this occurring, surgery should not be delayed by gathering ICP data. Operative intervention ranged from wound debridement and small craniotomy to full decompressive craniectomy with duraplasty. Indications for decompressive craniectomy included, but were not limited to, significant preoperative midline shift as a result of cerebral edema and/or intracranial hematoma, intraoperative or anticipated postoperative brain swelling (preemptive decompressive craniectomy), or intractable intracranial hypertension occurring after primary debridement and not responsive to maximum medical management.

\section{Data Collection and Analysis}

Patient demographics, initial neurological examination results and Glasgow Coma Scale (GCS) score, initial ICP (if applicable), vital signs, initial trauma laboratory values, and details of the hospital stay were obtained from the chart review. Initial CT findings were analyzed for the following: 1) penetration of the deep nuclei (thalamus, caudate, putamen, and globus pallidus) and/or third ventricle by bone or metallic fragments; 2) any shift of the midline structures; 3 ) number of lobes penetrated (single lobe designation for infratentorial injury); 4) unilateral or bilateral hemispheric involvement; 5) intracranial compartments involved (supratentorial, infratentorial, or both); and 6) transventricular projectile trajectory. The St. Louis scale score, as detailed in the original publication, was calculated retrospectively for each patient. ${ }^{2}$ In summary, the score is composed of 9 items: 3 primary ( 3 points each), 3 secondary ( 2 points each), and 3 tertiary (1 point each) predictive criteria (Table 1). A maximum of 18 points is possible.

\section{Statistical Analysis}

Bivariate analyses using chi-square and Fisher's exact tests were performed to evaluate individual effects of each clinical and radiological criterion against overall survival: 1) ICP $>30 \mathrm{~cm} \mathrm{H}_{2} \mathrm{O}$; 2) bilateral fixed pupils; 3) systolic blood pressure (SBP) < $100 \mathrm{~mm} \mathrm{Hg}$; 4) hematocrit < 30\%; 5) base deficit $<-5 \mathrm{mEq} / \mathrm{L}$; 6) international normalized ratio (INR) $>1.5 ; 7$ ) deep nuclear and/or third ventricular injury; 8) mixed supra-/infratentorial injury; 9) injury to $\geq$ 3 lobes, transventricular projectile trajectory; 10) bihemi- 
TABLE 1. St. Louis Scale for Pediatric Gunshot Wounds to the Head $^{*}$

\begin{tabular}{lc}
\hline \multicolumn{1}{c}{ Predictive Criteria } & Description \\
\hline Primary (3 points each) & $\begin{array}{c}\text { Bilateral fixed pupils on arrival; involve- } \\
\text { ment of deep nuclei \&/or 3rd ventricle; } \\
\text { ICP }>30 ~ m m ~ H g\end{array}$ \\
\hline Secondary (2 points each) & $\begin{array}{c}\text { Mixed supra-/infratentorial involvement; } \\
\text { at least 3 lobes involved (single lobe } \\
\text { for cerebellum); transventricular injury }\end{array}$ \\
\hline Tertiary (1 point each) & $\begin{array}{c}\text { Bihemispheric injury; SBP }<100 \mathrm{~mm} \mathrm{Hg} \\
\text { on arrival; midline shift }\end{array}$ \\
\hline
\end{tabular}

SBP = systolic blood pressure.

* The points for each applicable criterion are summed for a total possible score of 18. Modified from Bandt et al: J Neurosurg Pediatr 10:511-517, 2012.

Published with permission.

spheric injury; and 11) midline shift. For age comparison, the cohort was divided into 2 groups: those $0-9$ years and those $10-18$ years. An $\alpha$ value of 0.05 was chosen for statistical significance. Statistical analysis was performed using commercially available software (Prism 6.0, GraphPad).

\section{Results}

\section{Demographics and Presentation}

Seventy-one pediatric patients with an intracranial GSW presented to 1 of 2 Level 1 trauma centers between January 1996 and December 2013. The demographics of this population are summarized in Table 2 . The majority (57 [80.3\%] of 71) were male, and the mean age at presentation was 14 years (range 19 months-18 years). The mean GCS score was $7.4 \pm 5.0$, with the frequency of scores on admission having a bimodal distribution (Fig. 1). Bilater-

TABLE 2. Patient demographics

\begin{tabular}{cc}
\hline \multicolumn{1}{c}{ Characteristic } & Value (\%) \\
\hline Sex & \\
\hline Male & $14(80.3)$ \\
\hline Female & \\
\hline Race & $34(47.9)$ \\
\hline African American & $27(38)$ \\
\hline White & $10(14.1)$ \\
\hline Hispanic & \\
\hline Age in yrs & $2(3)$ \\
\hline $0-2$ & $7(10)$ \\
\hline $3-8$ & $9(13)$ \\
\hline $9-12$ & $21(30)$ \\
\hline $13-15$ & $32(45)$ \\
\hline $16-18$ & $10(14.1)$ \\
\hline Etiology & $16(22.5)$ \\
\hline Self-inflicted suicide & $25(35.2)$ \\
\hline Self-inflicted accidental & $7(9.8)$ \\
\hline Assault by other & $13(18.3)$ \\
\hline Accidental by other &
\end{tabular}

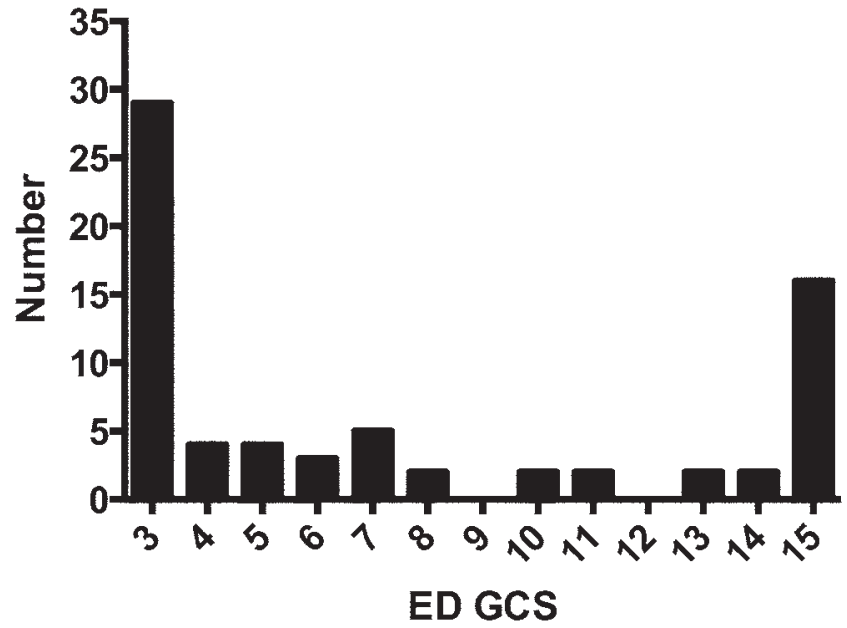

FIG. 1. Frequency of admission GCS scores in the Memphis cohort. ED = emergency department.

ally fixed pupils and anisocoria were present in 52\% (37 of 71 ) and $14 \%$ (10 of 71) of patients, respectively.

\section{Hospital Course}

Surgical intervention was performed in 39 patients (54.9\%). Eighteen patients underwent a craniotomy, including debridement of skin, skull, dura, and brain. Retained bone and metallic fragments that were easily accessible were removed. One patient developed a wound infection requiring debridement. Twenty-one patients underwent decompressive craniectomy either preemptively (18 patients) or secondarily (3 patients) because of refractory intracranial hypertension. Postoperative complications in this group included 5 wound infections requiring reoperation and 3 cerebrospinal fluid leaks.

Among survivors (37 patients), the mean duration of mechanical ventilation, stay in the intensive care unit, and overall hospital stay was 11.3 days (range $0-44$ days), 12.0 days (range 1-33 days), and 14.8 days (range 2-44 days), respectively. Overall, 22 patients were discharged home and 15 patients were discharged to a rehabilitation facility or unit.

\section{Outcome}

The overall mortality rate in this series of patients was $47.9 \%$ (34 of 71). Figure 2 shows the distribution of GOS scores overall and among those who underwent surgical intervention (39 patients), 2 of whom died postoperatively $(5.1 \%)$ and $30(76.9 \%)$ of whom had a good clinical outcome (GOS Score 4 or 5). As shown in Fig. 3, there was a linear relationship between GCS score at presentation and GOS score at the last follow-up.

The clinical and radiological findings of the survivors, stratified by either a poor (GOS Score 2 or 3, 7 patients) or a good (GOS Score 4 or 5, 30 patients) outcome, are listed in Table 3. In general, the children with a good clinical outcome had fewer of the noted findings than those with a poor outcome. It is difficult to draw meaningful conclusions regarding outcome prediction, however, given the relative scarcity of these findings among survivors. 


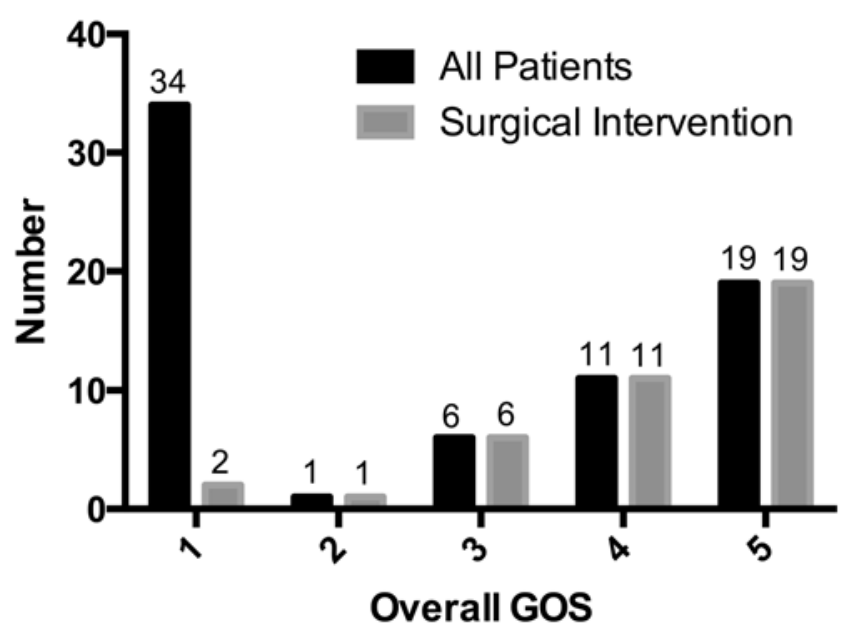

FIG. 2. Overall GOS scores of the study cohort and GOS scores after surgical intervention. GOS scores: 1 = death; 2 = persistent vegetative state; 3 = dependent, severe disability; 4 = independent, minor disability; $5=$ normal, minimal disability.

\section{Predictors of Mortality}

Bivariate results are presented in Table 4 . Nine of the 16 variables tested were predictive of death $(\mathrm{p}<0.05)$.

\section{St. Louis Scale for Pediatric Gunshot Wounds to the Head}

The mean score on the St. Louis Scale for Pediatric Gunshot Wounds to the Head in children who survived and those who died was 2.8 (range $0-12$ ) and 10 (range $3-14$ ), respectively. Table 5 shows the average scores and range for the survivors by GOS score. Interestingly, there were 9 survivors (24.3\%) in the cohort whose St. Louis score was $\geq 5$. All of these patients underwent surgery at the time of presentation. Three of these patients had a GOS score of 4 (favorable outcome), 5 patients had a GOS score of 3, and 1 patient had a GOS score of 2 at last follow-up.

The results of our evaluation of the St. Louis scale as a diagnostic test are detailed in Table 6. For the purposes of evaluation, a score $\geq 5$ was considered a positive test predictive for death. The sensitivity of the scale was $94.12 \%$, while the specificity was $75.68 \%$. The positive predictive

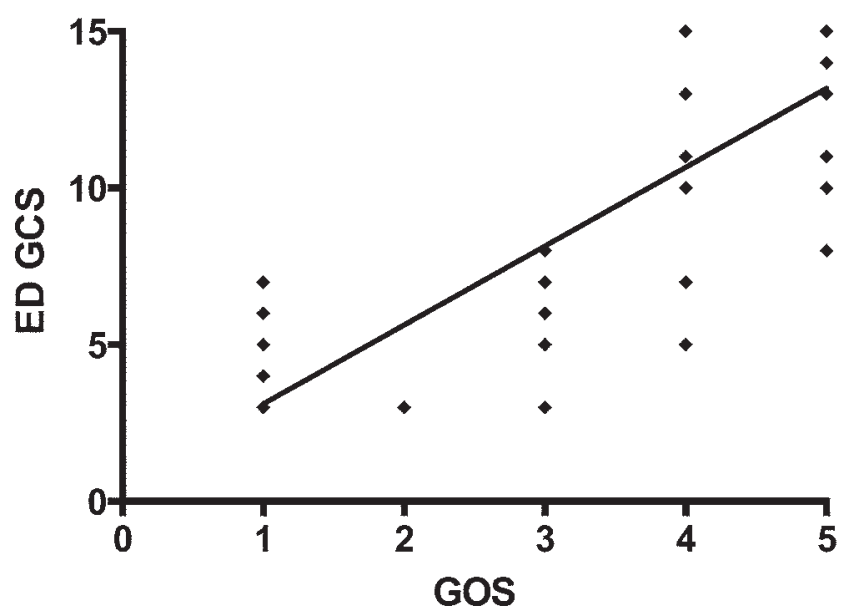

FIG. 3. Relationship of admission GCS score and overall GOS score.
TABLE 3. Clinical and radiological criteria of survivors

\begin{tabular}{lcc}
\hline \multicolumn{1}{c}{ Variable } & $\begin{array}{c}\text { GOS Score } \\
2 \text { or } 3\end{array}$ & $\begin{array}{c}\text { GOS Score } \\
4 \text { or } 5\end{array}$ \\
\hline $\mathrm{ICP}>30 \mathrm{~cm} \mathrm{H}_{2} \mathrm{O}$ & 1 & 1 \\
\hline $\mathrm{GCS}$ score & 4 & 2 \\
\hline $3-5$ & 3 & 4 \\
\hline $6-8$ & 2 & 0 \\
\hline Bilat fixed pupils & 2 & 0 \\
\hline SBP $<100$ mm Hg & 5 & 2 \\
\hline Hematocrit $<30 \%$ & 2 & 0 \\
\hline Base deficit $<-5.0$ mEq/L & 3 & 1 \\
\hline INR $>1.5$ & 7 & 3 \\
\hline Deep nuclear/3rd ventricular injury & 1 & 1 \\
\hline Mixed supra-/infratentorial injury & 7 & 4 \\
\hline Injury to $\geq 3$ lobes & 5 & 0 \\
\hline Transventricular trajectory & 5 & 0 \\
\hline Bihemispheric injury & 7 & 12 \\
\hline Midline shift & & \\
\hline Age in yrs & 1 & 26 \\
\hline $0-9$ & 6 & \\
\hline $10-18$ & & \\
\hline
\end{tabular}

value for death was $78.05 \%$. The negative predictive value (St. Louis score $\leq 4$ indicative of survival) was $93.33 \%$.

\section{Discussion}

\section{Our Results}

Children are not immune to gunshot injuries, intentional or accidental, that plague many cities across the US. When presented with a child who has sustained an intracranial GSW, the neurosurgeon must quickly decide whether the child has a fatal injury, an injury that is potentially nonfatal but very likely to have a devastating neurological outcome, or a survivable injury for which there is a reasonable chance of maintaining or regaining meaningful neurological function. The physician's appraisal of the neurological exam and imaging findings are then presented to the family and, in alignment with their wishes, a decision can be made on how to proceed with treatment. This process of determining what to do is more challenging in children than in adults owing to the former's young age and greater propensity to recover neurological function. This latter point is highlighted by the differences in brain death criteria between children and adults. ${ }^{21}$

Our series is one of the few that focuses on GSWs in children. Many reports of civilian cranial GSWs contain both pediatric and adult patients. We refer the reader to the paper by Bandt et al., ${ }^{2}$ which includes a tabulated summary of key articles. In their series of 82 children, Beaver et al. ${ }^{3}$ concluded that a child who has sustained a firearm injury is more likely to know the perpetrator, to be killed in the home by a readily available unsecured firearm, and to die of severe head injury. Paret et al. reported on 51 children and found admission GCS scores, CT findings of intraventricular hemorrhage and midline shift, and metabolic abnormalities to be of prognostic value. ${ }^{22}$ One 
TABLE 4. Bivariate testing of clinical and radiological criteria

\begin{tabular}{lcccc}
\hline \multicolumn{1}{c}{ Variable } & Survived & Died & NNT & p Value \\
\hline ICP $>30 \mathrm{~cm} \mathrm{H}_{2} \mathrm{O}$ & 2 & 4 & 16 & 0.4077 \\
\hline GCS score* & & & & \\
\hline $3-5$ & 6 & 31 & 2 & $<0.0001 \dagger$ \\
\hline $6-8$ & 7 & 3 & 5 & 0.2219 \\
\hline Bilat fixed pupils & 2 & 25 & 2 & $<0.0001 \dagger$ \\
\hline SBP $<100 \mathrm{~mm} \mathrm{Hg}$ & 2 & 13 & 4 & $0.009 \dagger$ \\
\hline Hematocrit $<30 \%$ & 4 & 13 & 4 & $0.006 \dagger$ \\
\hline Base deficit $<-5.0$ mEq/L & 5 & 15 & 4 & $0.0038 \dagger$ \\
\hline INR $>1.5$ & 2 & 3 & 12 & 0.0962 \\
\hline Deep nuclear/3rd ventricular & 10 & 26 & 2 & $<0.0001 \dagger$ \\
$\quad$ injury & & & & \\
\hline Mixed supra-/infratentorial injury & 2 & 6 & 8 & 0.1346 \\
\hline Injury to $\geq 3$ lobes & 10 & 19 & 4 & $0.0084 \dagger$ \\
\hline Transventricular trajectory & 5 & 26 & 2 & $<0.0001 \dagger$ \\
\hline Bihemispheric injury & 5 & 26 & 2 & $<0.0001 \dagger$ \\
\hline Midline shift & 19 & 22 & 7 & 0.1697 \\
\hline Age in yrs & & & & \\
\hline 0-9 & 5 & 5 & 41 & 0.8853 \\
\hline 10-18 & 32 & 29 & 41 & 0.8853 \\
\hline
\end{tabular}

NNT = number needed to treat.

* All patients with GCS score $>8$ survived.

$\dagger$ Statistically significant.

of the largest series known to us is by Levy et al., which comprised 105 children treated at the University of Southern California/Los Angeles County Medical Center. ${ }^{17}$ The majority of the children in that series $(72 \%)$ were treated for gang-related injuries, and patient age, sex, GCS score, projectile entry site, and bihemispheric injury were predictive variables.

We found that certain clinical (admission GCS score $\leq 5$, bilateral fixed and dilated pupils), laboratory (initial hematocrit $<30 \%$, base deficit $<-5 \mathrm{mEq} / \mathrm{L}$ ), and CT (deep nuclear/third ventricular injury, injury to $\geq 3$ lobes, transventricular injury, bihemispheric injury) results were statistically associated with death. An age less than 9 years, an initial ICP $>30 \mathrm{~cm} \mathrm{H}_{2} \mathrm{O}$ (or $\mathrm{mm} \mathrm{Hg}$ ), both supra- and infratentorial injury, and midline shift were not predictive.

Several other reports emphasize the importance of the GCS score at presentation in management decision making. $5,7,8,10,16,17,22,23,26$ While our data do demonstrate a sig-

TABLE 5. St. Louis Scale for Pediatric Gunshot Wounds to the Head scores in 71 patients with GSWs

\begin{tabular}{cc}
\hline Group & Mean Score (range) \\
\hline Survivors & $2.8(0-12)$ \\
\hline GOS Score 2 & $12(\mathrm{NA})$ \\
\hline GOS Score 3 & $8.5(0-12)$ \\
\hline GOS Score 4 & $2.8(0-9)$ \\
\hline GOS Score 5 & $0.4(0-2)$ \\
\hline Nonsurvivors & $10(3-14)$ \\
\hline
\end{tabular}

$\mathrm{NA}=$ not applicable.
TABLE 6. Evaluation of the St. Louis scale

\begin{tabular}{lcc}
\hline \multicolumn{1}{c}{ Statistic } & Value & $95 \% \mathrm{Cl}$ \\
\hline Sensitivity & $94.12 \%$ & $80.29 \%-99.11 \%$ \\
\hline Specificity & $75.68 \%$ & $58.80 \%-88.20 \%$ \\
\hline Positive likelihood ratio* & 3.87 & $2.18-6.87$ \\
\hline Negative likelihood ratio & 0.08 & $0.02-0.30$ \\
\hline Death prevalence & $47.89 \%$ & $35.88 \%-60.08 \%$ \\
\hline PPV & $78.05 \%$ & $62.38 \%-89.42 \%$ \\
\hline NPV & $93.33 \%$ & $77.89 \%-98.99 \%$ \\
\hline
\end{tabular}

$\mathrm{NPV}=$ negative predictive value $\mathrm{PPV}=$ positive predictive value

* Positive test defined as St. Louis score $\geq 5$.

$\dagger$ Negative test defined as St. Louis score $\leq 4$.

nificant association between a GCS score $\leq 5$ and overall mortality, we do not recommend using a strict GCS cutoff score alone because of the potential inaccuracy of the admission GCS score in a patient whose neurological function is depressed iatrogenically or in response to inadequate volume resuscitation or hypothermia. In agreement with other authors, we found a strong association between bilaterally fixed pupils and death. ${ }^{10,23,26}$ The significant association of anemia (hematocrit $<30 \%$ ) and intravascular volume depletion (base deficit $<-5 \mathrm{mEq} / \mathrm{L}$ ) with mortality reflects the critical importance of rapid correction with fluid and/or blood. Coagulopathy at presentation (INR > 1.5) was not significantly associated with death, probably given the fact that temporary coagulopathy is not as potentially damaging to the at-risk brain as hypotension and that the coagulopathy can usually be readily reversed with transfusion of plasma. The lack of an association between intracranial hypertension (ICP $>30 \mathrm{~cm} \mathrm{H}_{2} \mathrm{O}$ ) and death is due to inadequate data given our bias for upfront surgery versus ICP monitoring. Although preoperative ICP monitoring was rarely performed, it was routinely used postoperatively.

Similar to the radiological criteria set forth in the St. Louis scale, our data support the ominous findings of deep nuclear/third ventricular injury and transventricular trajectory. The predictive value of transventricular and transhemispheric missile injuries has been reported extensively in the literature on adults., $4,5,8,13,14,25,26,28$ Mixed supratentorial/infratentorial injury did not reach statistical significance-again because of a lack of data-but it should be noted that this injury was associated with $75 \%$ mortality. In contrast to Bandt et al., ${ }^{2}$ we found that midline shift was not associated with mortality. This finding may be attributable to the fact that this criterion was a binary variable (yes/no) as opposed to a cutoff value. For example, a midline shift $>5 \mathrm{~mm}$ is a more significant finding than a shift of 1-2 mm. Furthermore, as stated previously, our threshold in performing a craniectomy was low, which meant that children with midline shift were often rapidly taken for decompression, which would have relieved the midline shift and intracranial hypertension to a greater degree than medical management.

Another important but often immeasurable factor in determining the extent of tissue damage and neurological injury is the muzzle energy, which is the kinetic energy of the projectile upon exiting the barrel of the weapon. It is 
directly proportional to the weight (or "grain") of the bullet, but more importantly the velocity as kinetic energy = $1 / 2 \times$ mass $\times$ velocity $^{2}$. The greater energy the projectile has upon impact, the greater energy that is dissipated to the surrounding tissue, causing cavitation injury. It is rare that the actual bullet is recovered from the patient, and if it is, it is often a small-caliber bullet ( 0.22 to 0.38 caliber) from a low-muzzle-velocity weapon (900 to $1300 \mathrm{ft} / \mathrm{sec}){ }^{5}$

In the pediatric population, published mortality rates from intracranial GSWs range from $20 \%$ to $60 \%$. $2,7,11,16,17,19,22$ The mortality rate of our cohort fell within this range (47.9\%) and was lower than the mortality reported by Bandt and colleagues (65\%). ${ }^{2}$ Unfortunately, those authors did not provide a breakdown of the proportion of patients undergoing surgery. In our cohort, $54.9 \%$ of patients underwent surgical intervention. Of the survivors, $81 \%$ showed only minor disability or better at the last follow-up (GOS Score 4 or 5). This rate is comparable with the results from the St. Louis study in which $88 \%$ of survivors had a GOS score of 4 or $5 .^{2}$

\section{St. Louis Scale for Pediatric Gunshot Wounds to the Head}

A number of prognostic scales have been proposed to help in determining the viability of patients with cranial GSWs. ${ }^{8,9,18,28,30}$ The St. Louis scale is the only one that we know of that is specific for children and marks a significant contribution to the literature. ${ }^{2}$ In Bandt and colleagues' series, a St. Louis scale score $\leq 4$ was associated with a positive predictive value of $88.9 \%$ for survival; a score $\geq 5$ was associated with a negative predictive value of $96.7 \%$ for death. The sensitivity of the scale, using the St. Louis cohort, was $93.55 \%$ and the specificity of the scale was $94.12 \%$.

The mean St. Louis score for the nonsurvivors in our cohort was 10 , which is in general agreement with the utility of the scale. However, the mean St. Louis score for the group with a GOS score of 3 was 8.5 , which demonstrates that some patients with a St. Louis score $\geq 5$ can and will survive. In fact, 9 survivors had St. Louis scores $\geq 5$. Of these 9 patients, 3 had a GOS score of 4 at the last follow-up and 5 had a GOS score of 3 . While severe disability may be considered an unfavorable outcome by some (and probably more so for an adult patient), many families would disagree with this sentiment when faced with the imminent death of their child. Upon further investigation into this subgroup of the cohort, the higher St. Louis scores were primarily attributable to deep nuclear injury and bihemispheric injury without transventricular trajectory. Additional points were gained from low SBP and midline shift. As such, some survivors with the potential for a favorable outcome may be missed if judged by the St. Louis scale score alone.

Using our patient population, we determined that the St. Louis scale was sensitive (94.12\%), but lacked specificity for death as an outcome (75.68\%). A score $\geq 5$ was associated with a positive predictive value of $78.05 \%$ for death; a score $\leq 4$ was associated with a negative predictive value of $93.33 \%$ for death (in other words $93.33 \%$ predictive for survival). Therefore, we conclude that the St. Louis scale is more useful for determining those who will survive (score $\leq 4)$ rather than those who will die (score $\geq 5$ ). Unfortu- nately, the more difficult decisions involve the children whose St. Louis scale score is greater than 5 .

\section{Study Limitations}

A retrospective study design is always touted as a limitation, but it is difficult to conduct a prospective singlecenter study on an event that occurs with an average frequency of 4 patients per year. Even though our series is one of the larger ones, it still has a relatively small number of patients, which limits the strength of our findings and conclusions.

\section{Conclusions}

In Memphis and other large metropolitan communities, pediatric intracranial GSWs are an unfortunate reality. In this study, $52 \%$ of children with an intracranial GSW survived with aggressive surgical and medical care, and $81 \%$ of survivors had a favorable outcome (GOS Score 4 or 5) at the last follow-up. The utility of several clinical, laboratory, and radiological prognostic factors were verified. None of these factors, with the exception of bilateral fixed and dilated pupils, should be used alone to determine prognosis and treatment, but instead all factors should be considered together as they have greater predictive power collectively. When used in our population as a predictive tool, the St. Louis Scale for Pediatric Gunshot Wounds to the Head was superior at forecasting survival after a gunshot injury rather than death.

\section{Acknowledgments}

We thank Andrew J. Gienapp for technical and copyediting preparation of the manuscript and figures and for publication assistance with this manuscript.

\section{References}

1. Aarabi B, Tofighi B, Kufera JA, Hadley J, Ahn ES, Cooper C, et al: Predictors of outcome in civilian gunshot wounds to the head. J Neurosurg 120:1138-1146, 2014

2. Bandt SK, Greenberg JK, Yarbrough CK, Schechtman KB, Limbrick DD, Leonard JR: Management of pediatric intracranial gunshot wounds: predictors of favorable clinical outcome and a new proposed treatment paradigm. J Neurosurg Pediatr 10:511-517, 2012

3. Beaver BL, Moore VL, Peclet M, Haller JA Jr, Smialek J, Hill JL: Characteristics of pediatric firearm fatalities. J Pediatr Surg 25:97-100, 1990

4. Cavaliere R, Cavenago L, Siccardi D, Viale GL: Gunshot wounds of the brain in civilians. Acta Neurochir (Wien) 94:133-136, 1988

5. Clark WC, Muhlbauer MS, Watridge CB, Ray MW: Analysis of 76 civilian craniocerebral gunshot wounds. J Neurosurg 65:9-14, 1986

6. Coronado VG, Xu L, Basavaraju SV, McGuire LC, Wald MM, Faul MD, et al: Surveillance for traumatic brain injuryrelated deaths-United States, 1997-2007. MMWR Surveill Summ 60:1-32, 2011

7. Coughlan MD, Fieggen AG, Semple PL, Peter JC: Craniocerebral gunshot injuries in children. Childs Nerv Syst 19:348-352, 2003

8. Grahm TW, Williams FC Jr, Harrington T, Spetzler RF: Civilian gunshot wounds to the head: a prospective study. Neurosurgery 27:696-700, 1990 
9. Gressot LV, Chamoun RB, Patel AJ, Valadka AB, Suki D, Robertson CS, et al: Predictors of outcome in civilians with gunshot wounds to the head upon presentation. J Neurosurg 121:645-652, 2014

10. Hofbauer M, Kdolsky R, Figl M, Grünauer J, Aldrian S, Ostermann RC, et al: Predictive factors influencing the outcome after gunshot injuries to the head-a retrospective cohort study. J Trauma 69:770-775, 2010

11. Irfan FB, Hassan RU, Kumar R, Bhutta ZA, Bari E: Craniocerebral gunshot injuries in preschoolers. Childs Nerv Syst 26:61-66, 2010

12. Joseph B, Aziz H, Pandit V, Kulvatunyou N, O'Keeffe T, Wynne J, et al: Improving survival rates after civilian gunshot wounds to the brain. J Am Coll Surg 218:58-65, 2014

13. Kaufman HH: Civilian gunshot wounds to the head. Neurosurgery 32:962-964, 1993

14. Kim KA, Wang MY, McNatt SA, Pinsky G, Liu CY, Giannotta SL, et al: Vector analysis correlating bullet trajectory to outcome after civilian through-and-through gunshot wound to the head: using imaging cues to predict fatal outcome. Neurosurgery 57:737-747, 2005

15. Krieger MD, Levy ML, Apuzzo ML: Gunshot wounds to the head in an urban setting. Neurosurg Clin N Am 6:605-610, 1995

16. Levy ML: Outcome prediction following penetrating craniocerebral injury in a civilian population: aggressive surgical management in patients with admission Glasgow Coma Scale scores of 6 to 15. Neurosurg Focus 8(1):e2, 2000

17. Levy ML, Masri LS, Levy KM, Johnson FL, Martin-Thomson E, Couldwell WT, et al: Penetrating craniocerebral injury resultant from gunshot wounds: gang-related injury in children and adolescents. Neurosurgery 33:1018-1025, 1993

18. Martins RS, Siqueira MG, Santos MT, Zanon-Collange N, Moraes OJ: Prognostic factors and treatment of penetrating gunshot wounds to the head. Surg Neurol 60:98-104, 2003

19. Miner ME, Ewing-Cobbs L, Kopaniky DR, Cabrera J, Kaufmann P: The results of treatment of gunshot wounds to the brain in children. Neurosurgery 26:20-25, 1990

20. Murano T, Mohr AM, Lavery RF, Lynch C, Homnick AT, Livingston DH: Civilian craniocerebral gunshot wounds: an update in predicting outcomes. Am Surg 71:1009-1014, 2005

21. Nakagawa TA, Ashwal S, Mathur M, Mysore M: Clinical report-Guidelines for the determination of brain death in infants and children: an update of the 1987 task force recommendations. Pediatrics 128:e720-e740, 2011

22. Paret G, Barzilai A, Lahat E, Feldman Z, Ohad G, Vardi A, et al: Gunshot wounds in brains of children: prognostic variables in mortality, course, and outcome. J Neurotrauma 15:967-972, 1998
23. Petridis AK, Doukas A, Barth H, Mehdorn M: Outcome of craniocerebral gunshot injuries in the civilian population. Prognostic factors and treatment options. Cent Eur Neurosurg 72:5-14, 2011

24. Prasad MR, Ewing-Cobbs L, Swank PR, Kramer L: Predictors of outcome following traumatic brain injury in young children. Pediatr Neurosurg 36:64-74, 2002

25. Selden BS, Goodman JM, Cordell W, Rodman GH Jr, Schnitzer PG: Outcome of self-inflicted gunshot wounds of the brain. Ann Emerg Med 17:247-253, 1988

26. Shaffrey ME, Polin RS, Phillips CD, Germanson T, Shaffrey CI, Jane JA: Classification of civilian craniocerebral gunshot wounds: a multivariate analysis predictive of mortality. $\mathbf{J}$ Neurotrauma 9 (Suppl 1):S279-S285, 1992

27. Siccardi D, Cavaliere R, Pau A, Lubinu F, Turtas S, Viale GL: Penetrating craniocerebral missile injuries in civilians: a retrospective analysis of 314 cases. Surg Neurol 35:455-460, 1991

28. Stone JL, Lichtor T, Fitzgerald LF: Gunshot wounds to the head in civilian practice. Neurosurgery 37:1104-1112, 1995

29. Pruitt BA Jr (ed): Surgical management of penetrating brain injury. J Trauma 51 (2 Suppl):S16-S25, 2001

30. Turina D, Sustić A, Tićac Z, Dirlić A, Krstulović B, Glavas A, et al: War head injury score: an outcome prediction model in War casualties with acute penetrating head injury. Mil Med 166:331-334, 2001

31. Zafonte RD, Wood DL, Harrison-Felix CL, Valena NV, Black K: Penetrating head injury: a prospective study of outcomes. Neurol Res 23:219-226, 2001

\section{Disclosures}

The authors report no conflict of interest concerning the materials or methods used in this study or the findings specified in this paper.

\section{Author Contributions}

Conception and design: all authors. Acquisition of data: DeCuypere. Analysis and interpretation of data: Klimo, DeCuypere. Drafting the article: Klimo, DeCuypere. Critically revising the article: all authors. Reviewed submitted version of manuscript: all authors. Approved the final version of the manuscript on behalf of all authors: Klimo. Study supervision: Klimo.

\section{Correspondence}

Paul Klimo Jr., Semmes-Murphey Neurologic \& Spine Institute, 6325 Humphreys Blvd., Memphis, TN 38120.email: pklimo@ semmes-murphey.com. 